\title{
Simply wearing footwear could interrupt transmission of Strongyloides stercoralis
}

\author{
David N Durrheim professor of public health and tropical medicine
}

Anton Breinl Centre, James Cook University, Douglas, Townsville, Qld, Australia

Greaves and colleagues provide a valuable overview of the pathophysiology, clinical manifestations, and current approaches to the diagnosis and treatment of Strongyloides stercoralis infection. ${ }^{1}$ Inexplicably they do not mention the measures needed to interrupt the transmission cycle by ensuring that faeces are disposed of safely. Possibly this is the result of embarrassment at our tardy global progress towards meeting the sanitation component of millennium development goal number 7 .

The World Health Organization seems to have thrown its arms up in despair with a defeatist: "No public health strategies for controlling the disease are active at the global level." It is therefore hardly surprising that some consider this soil transmitted helminth infection to be the most neglected of neglected tropical diseases, infecting up to 100 million people worldwide. ${ }^{3}$

Preventive chemotherapy approaches are now being advocated, but are we overlooking the obvious? Time honoured public health tradition argues that the cycle of transmission could be interrupted by simply wearing footwear. This has been supported by compelling scientific evidence from high risk environments. ${ }^{45}$
The considerable recent investment in diagnostic and therapeutic research into neglected tropical diseases should extend to providing culturally appropriate education and protective footwear in high risk communities.

Competing interests: None declared.

Greaves D, Coggle S, Pollard C, Aliyu SH, Moore EM. Strongyloides stercoralis infection BMJ 2013;347:44610. (30 July.)

2 WHO. Neglected tropical diseases. Strongyloidiasis. www.who.int/neglected_diseases/ diseases/strongyloidiasis/en/.

3 Olsen A, van Lieshout L, Marti H, Polderman T, Polderman T, Polman K, et al Strongyloidiasis-the most neglected of the neglected tropical diseases? Trans $R$ Soc Trop Med Hyg 2009;103:967-72.

4 Krolewiecki AJ, Lammie P, Jacobson J, Gabrielli A-F, Gabrielli AF, Levecke B, et al. A public health response against Strongyloides stercoralis: time to look at soil-transmitted helminthiasis in full. PLoS Negl Trop Dis 2013;7:e2165.

5 Yori PP, Kosek M, Gilman RH, Cordova J, Cordova J, Bern C, et al. Seroepidemiology of strongyloidiasis in the Peruvian Amazon. Am J Trop Med Hyg 2006;74:97-102.

Cite this as: BMJ 2013;347:f5219

(c) BMJ Publishing Group Ltd 2013 